\title{
Innovative trend analysis of rainfall in relation to soybean productivity over western Maharashtra

\author{
R.N. SINGH ${ }^{1 *}$, SONAM SAH ${ }^{2}$, GAURAV CHATURVEDI ${ }^{2}$, BAPPA DAS $^{3}$ and H. PATHAK ${ }^{1}$ \\ ${ }^{1}$ ICAR- National Institute of Abiotic Stress Management, Baramati, Maharashtra \\ ${ }^{2}$ G. B. Pant University of Agriculture \& Technology, Pantnagar, Uttarakhand \\ ${ }^{3}$ ICAR - Central Coastal Agricultural Research Institute, Goa \\ *Corresponding author: rns.iari@gmail.com
}

\begin{abstract}
This study examined and compared the new innovative trend analysis (ITA) of monthly, seasonal and annual rainfall with traditional trend analysis methods in relation to soybean productivity in western Maharashtra. Spearman's rank correlation, Mann-Kendall and its 6 different modifications were used to analyze the trends of rainfall, whereas Spearman's rho, simple linear regression and Sen's slope with two different modifications were employed to quantify the magnitude of trends at $1 \%, 5 \%$ and $10 \%$ level of significance. Autocorrelation coefficient was calculated at lag- 1 and tested at $5 \%$ level of significance. Rainfall variability of the region is very high $(C V>30)$ in all the months and seasons with positively skewed rainfall distribution. Our results revealed that out of 34-time series data analyzed, ITA was able to ide ntify all the significant trends (11 -time series) that can be detected by traditional methods. Meanwhile, ITA also identified trends in 17-time series which cannot be detected by any of the traditional methods. The study revealed significant increase in monsoon and annual rainfall values, which is helpful in sustaining soybean productivity in the western parts of the Maharashtra.
\end{abstract}

Key words: Innovative trend analysis, rainfall, autocorrelation, Mann-Kendall, Spearman's rho

Climate change has significant consequences on the amount of rainfall and its distribution. The temporal pattern and variability of rainfall also play a vital role in modelling the processes in hydrology, climatology and agriculture. At present, there are many traditional methods to detect meteorological time series trends, such as linear regression analysis (SLR), Mann-Kendall and Modified Mann-Kendall tests, Sen's slope (SS) and Spearman's rank correlation test. Innovative trend analysis (ITA) is recently developed by Sen (2012), and several applications of the ITA method have been found for identifying the trend in meteorological time series data (Şen, 2012).Several rainfall trend detection analyses were also conducted in India using these tests (Sinha et al., 2020). However, most of them analyzed the rainfall trends using very few methods such as one parametric test (least square regression) and one non-parametric test (MannKendall) with independent observations assumption which is not valid in the case of basic hydrological variables like rainfall. If the serial correlation of the data is not taken into consideration, it can lead to inaccurate and misleading results. From the literature review, it's evident that none of the methods are perfect for trend detection and have their own advantages and disadvantages. To cover this lacuna, our analysis approach will be comprising traditional approaches including MK, MMK (6 modifications), SSestimator (with 2 modifications), SRC and SLR tests, along with the new ITA for detecting trend and its magnitude. The objective of the study is to analyze and compare the results of long term trends obtained from ITA and traditional methods in relation to soybean productivity in western Maharashtra. This detailed micro-analysis will also give a broad overview of changing climate and its effect on rainfall and agriculture in the study area.

\section{MATERIAL AND METHODS}

\section{Data used}

The study was conducted using 51 years (19692019) of rainfall data of two meteorological stations, i.e., Baramati $\left(18.15^{\circ} \mathrm{N} \& 74.58^{\circ} \mathrm{E}\right)$ and Shivajinagar (18.54 $\left.{ }^{\circ} \mathrm{N} \& 73.84^{\circ} \mathrm{E}\right)$ located in the western part of Maharashtra. The monthly rainfall data were cumulated over the winter (January-February), pre-monsoon (March-May), monsoon (June-September) and post-monsoon (October-December) seasons to obtain the seasonal and annual rainfall. 


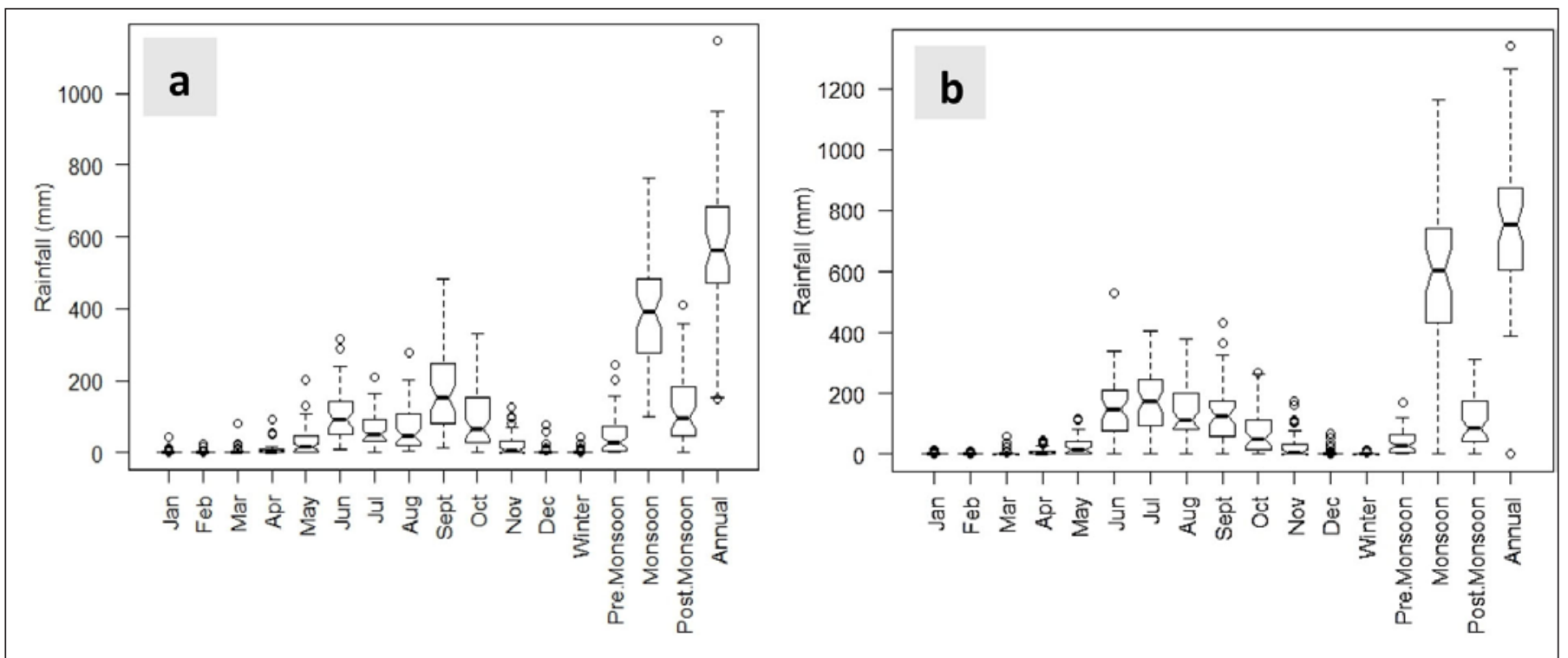

Fig. 1: Temporal variations of monthly, seasonal and annual rainfall at (a) Baramati and (b) Shivajinagar.

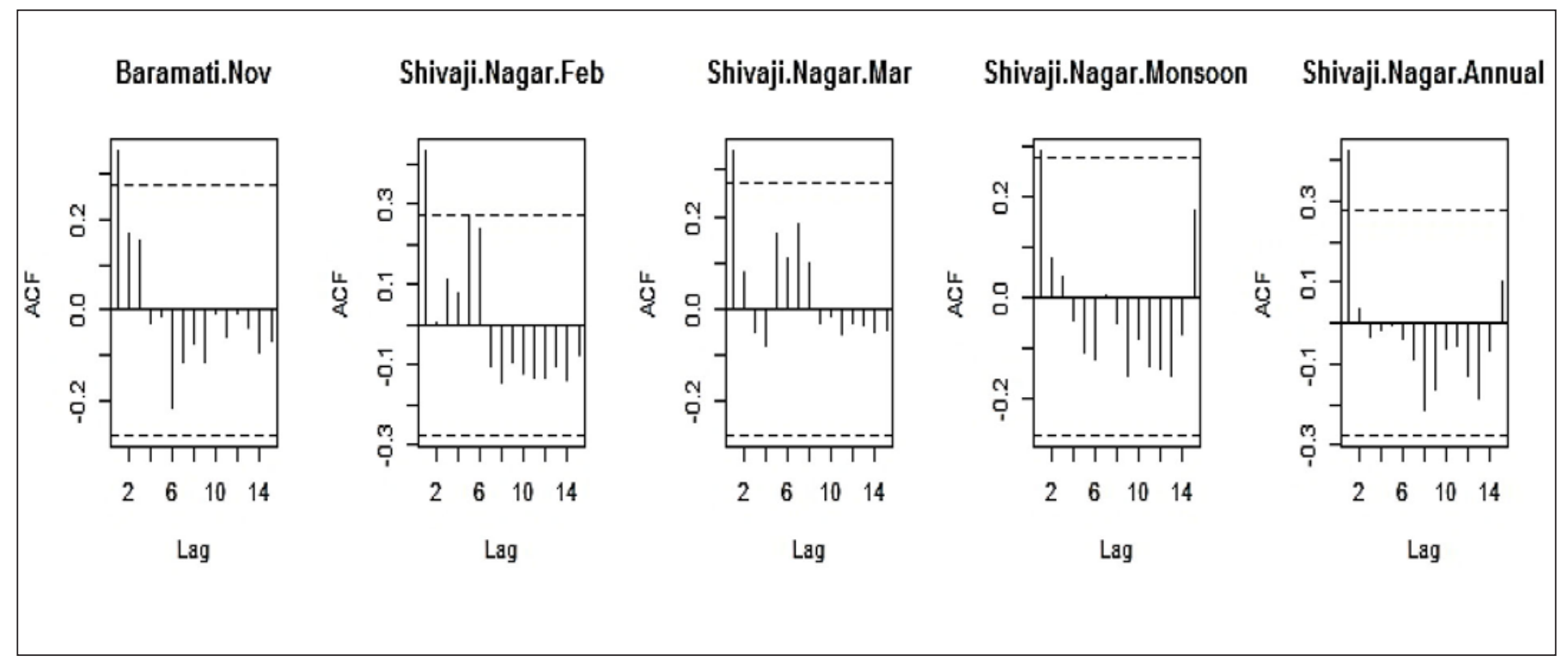

Fig. 2: Correlogram of observed rainfall data with significant autocorrelations.

\section{De-trended soybean productivity}

Soybean kharif season yield data ( $\mathrm{t} / \mathrm{ha})$ has been collected from Directorate of Economics and Statistics, Ministry of Agriculture and Farmers Welfare, for the period 1999-2018. To remove the effect of non-meteorological parameters, the observed yields were de-trended using a simple linear model (Subash and Ram Mohan, 2012).

\section{Autocorrelation}

The significant autocorrelation in the rainfall data was calculated, as proposed by Haan (2002). The correlograms of significant autocorrelations are shown in Fig. 2. Only the positive autocorrelation coefficients (ACC) were significant at $5 \%$ level.

\section{Spearman's rank correlation (SRC) test}

Spearman's rank correlation (Spearman's $\rho$ ) is a non-parametric test of trend detection. Lehmann \&D’Abrera (1975) and Sneyers (1990) expressed its statistic $\rho$ (Spearman's $\rho, \mathrm{SR})$ and the standardized test statistic Z $\left(\mathrm{Z}_{\mathrm{SR}}\right)$.

\section{Mann-Kendall (MK) and Modified Mann-Kendall (MMK)}

The Mann-Kendall (MK) test (Mann, 1945; Kendall, 1975) is a non-parametric trend test applied to identify noteworthy trends in a time series. To address the issue of autocorrelation in the data, trend tests were applied to the modified versions of the time series. The following MMK tests were used in this study: (1) MMK1: The Hamed and 
Table 1: Statistical summary of monthly, seasonal and annual rainfall in Baramati and Shivajinagar

\begin{tabular}{lrrrrrrrrrr}
\hline & \multicolumn{4}{c}{ Baramati } & \multicolumn{4}{c}{ Shivajinagar } \\
\hline Month/ Season & \multicolumn{1}{c}{ Mean } & \multicolumn{1}{c}{ SD } & \multicolumn{1}{c}{ CV } & \multicolumn{1}{c}{ CS } & \multicolumn{1}{c}{ CK } & \multicolumn{1}{c}{ Mean } & \multicolumn{1}{c}{ SD } & \multicolumn{1}{c}{ CV } & CS & CK \\
\hline January & 1.53 & 6.34 & 413.69 & 5.58 & 35.60 & 1.07 & 2.79 & 259.92 & 3.26 & 14.20 \\
February & 1.16 & 4.24 & 364.61 & 4.34 & 21.64 & 0.95 & 2.29 & 239.88 & 2.77 & 10.40 \\
March & 4.68 & 12.57 & 268.46 & 4.58 & 27.12 & 4.22 & 10.73 & 254.21 & 3.63 & 16.78 \\
April & 8.36 & 17.31 & 206.99 & 3.13 & 13.06 & 8.85 & 12.49 & 141.01 & 1.59 & 4.52 \\
May & 33.16 & 41.32 & 124.60 & 1.89 & 7.29 & 26.69 & 29.86 & 111.84 & 1.24 & 3.97 \\
June & 101.02 & 67.27 & 66.60 & 1.07 & 4.31 & 155.14 & 100.35 & 64.68 & 1.07 & 5.08 \\
July & 65.46 & 48.38 & 73.90 & 0.96 & 3.33 & 173.41 & 93.59 & 53.97 & 0.30 & 2.36 \\
August & 69.85 & 64.18 & 91.87 & 1.17 & 3.82 & 138.00 & 85.45 & 61.92 & 0.72 & 2.93 \\
September & 166.91 & 112.45 & 67.37 & 0.80 & 3.10 & 133.40 & 95.42 & 71.53 & 1.02 & 3.86 \\
October & 98.86 & 88.76 & 89.78 & 0.90 & 2.92 & 76.11 & 73.68 & 96.80 & 0.94 & 2.97 \\
November & 20.00 & 29.48 & 147.45 & 1.87 & 5.96 & 25.59 & 41.81 & 163.37 & 2.13 & 7.01 \\
December & 4.35 & 13.52 & 310.87 & 4.20 & 20.39 & 5.56 & 14.60 & 262.73 & 2.89 & 10.73 \\
Winter & 2.69 & 7.75 & 287.61 & 3.58 & 16.37 & 2.03 & 3.56 & 175.71 & 1.75 & 5.27 \\
Pre-monsoon & 46.21 & 53.66 & 116.13 & 1.72 & 6.02 & 39.77 & 36.81 & 92.57 & 1.25 & 4.83 \\
Monsoon & 403.24 & 155.32 & 38.52 & 0.40 & 2.56 & 599.95 & 215.14 & 35.86 & 0.16 & 3.50 \\
Post-monsoon & 123.21 & 98.28 & 79.77 & 1.13 & 3.64 & 107.26 & 87.23 & 81.33 & 0.74 & 2.56 \\
Annual & 575.35 & 194.84 & 33.87 & 0.28 & 3.63 & 749.01 & 232.93 & 31.10 & -0.14 & 4.37 \\
\hline
\end{tabular}

SD: Standard Deviation, CV: Coefficient of variation, CS: Coefficient of Skewness, CK: Coefficient of Kurtosis

Ramachandra Rao (1998) variance correction approach was used and the de-trended time series was constructed using Sen's slope and the lag-1 ACC. (2) MMK2: The method is a modification of MMK1 and instead of using only lag -1 $\mathrm{ACC}$, it uses the first three ACC, as proposed by Rao et al., (2012). (3) MMK3: The Yue and Wang (2004) variance correction approach was used in this method. ACC for all lags is used in calculating the effective sample size. (4) MMK4: This method follows MMK3 with the lag-1 ACC only. The effective sample size is in trend detection method is calculated using the lag-1 ACC. (5) MMK5: This method is based on the Mann-Kendall test of prewhitened time series using the Von Storch (1999) approach. The lag-1 ACC is used for pre-whitening the data (Yue and Wang, 2002). (6) MMK6: In this method, the Mann-Kendall trend test applied to trend free pre-whitened time series data in the presence of serial correlation using Yue et al., (2002) approach.

\section{Sen's slope estimator and Simple linear regression}

The Sen's slope (SS1) estimator is a non-parametric test that is used to estimate the true slope (magnitude) of the trend (Sen, 1968). SS2 and SS3 is Sen's slope of prewhitened time series using the von Storch (1999) and Yueet al., (2002) approach, respectively. The slope of simple linear regression (SL), one of the most commonly used parametric model, is also used to detect the trend in the time series data.

\section{Innovative trend analysis}

The innovative trend analysis (ITA) proposed by Sen (2012) was applied. The rainfall time series is divided into two equal parts from the first date to the end date. Both sub-series are sorted in ascending order, the first half series is located at the $\mathrm{X}$-axis and the second half series is placed at the Y-axis of the Cartesian coordinate system. If the data points collects on 1:1 line, there is no trend in the data. If the data points fall above the 1:1 line, it is indicative of a positive trend. If the data points accumulate below the $1: 1$ line, it indicates a negative trend.

The null hypothesis of no trend in the time series and alternate hypothesis of there is a trend in the time series in whole analysis are tested at three different significance levels $(\alpha)$, i.e., $\alpha=10 \%$ with $Z= \pm 1.64, \alpha=5 \%$ with $Z=$ \pm 1.96 and $\alpha=1 \%$ with $Z= \pm 2.58$.

\section{RESULTS AND DISCUSSION}

\section{Statistical characteristics of rainfall}

Descriptive statistical parameters including mean, standard deviation (SD), coefficients of skewness (CS), kurtosis (CK) and variation (CV) of monthly, seasonal and annual rainfall of both stations are summarized in Table 1. The mean monthly rainfall was maximum in September in Baramati and July in Shivajinagar. Shivajinagar has higher monsoon and annual rainfall than Baramati while premonsoon and post-monsoon rainfall were higher in Baramati 
Table 2: Results of the statistical tests for rainfall over the period 1969-2019 for Baramati

\begin{tabular}{|c|c|c|c|c|c|c|c|c|c|c|c|c|c|c|}
\hline Month /Season & $\mathrm{Z}_{\mathrm{MK}}$ & $Z_{\mathrm{MMK} 1}$ & $\mathrm{SS} 1$ & $Z_{\text {MMK2 }}$ & $Z_{\text {MMK } 3}$ & $Z_{\text {MMK4 }}$ & $Z_{\text {MMK5 }}$ & SS2 & $Z_{\text {MMK6 }}$ & SS3 & $\mathrm{Z}_{\mathrm{SR}}$ & SR & SL & SITA \\
\hline Feb & 0.477 & 0.461 & 0.000 & 0.477 & 1.464 & 0.515 & 0.537 & 0.000 & 0.537 & 0.000 & 0.509 & 0.072 & 0.000 & -0.01 \\
\hline Apr & 0.145 & 0.145 & 0.000 & 0.145 & 0.335 & 0.155 & 0.034 & 0.000 & 0.034 & 0.000 & 0.139 & 0.020 & -0.019 & -0.01 \\
\hline May & -0.253 & -0.253 & 0.000 & -0.253 & -0.685 & -0.232 & -0.586 & -0.069 & -0.586 & -0.069 & -0.311 & -0.044 & -0.002 & 0.18 \\
\hline Aug & -0.049 & -0.049 & -0.022 & -0.049 & -0.129 & -0.056 & 0.234 & 0.097 & 0.251 & 0.100 & -0.062 & -0.009 & -0.160 & 0.03 \\
\hline Sep & -0.227 & -0.307 & -0.135 & -0.227 & -0.720 & -0.226 & -0.017 & -0.031 & -0.033 & -0.032 & -0.225 & -0.032 & -0.277 & $-0.40 *$ \\
\hline Oct & 0.171 & 0.171 & 0.093 & 0.171 & 0.545 & 0.184 & -0.134 & -0.114 & -0.151 & -0.109 & 0.218 & 0.031 & 0.070 & $-0.38 * * *$ \\
\hline Nov & -0.139 & -0.139 & 0.000 & -0.139 & -0.182 & -0.097 & -0.017 & 0.000 & -0.017 & 0.000 & -0.190 & -0.027 & -0.343 & $-0.31 * * *$ \\
\hline Dec & 0.584 & 0.488 & 0.000 & 0.584 & 1.072 & 0.604 & 1.075 & 0.000 & 1.075 & 0.000 & 0.562 & 0.080 & -0.044 & -0.20 \\
\hline Post-monsoon & -0.593 & -0.773 & -0.442 & -0.593 & $-2.111 * *$ & -0.628 & -0.820 & -0.744 & -0.803 & -0.703 & -0.691 & -0.098 & -0.317 & $-0.88 * * *$ \\
\hline Annual & -0.049 & -0.049 & -0.083 & -0.049 & -0.144 & -0.044 & 0.402 & 0.731 & 0.402 & 0.715 & 0.081 & 0.011 & 0.850 & $0.63^{*}$ \\
\hline
\end{tabular}

* Significance at $\mathrm{p} \leq 0.1$; * significance at $\mathrm{p} \leq 0.05 ; * * *$ significance at $\mathrm{p} \leq 0.01$; Bold font represent trends identified only by ITA

as compared to Shivajinagar. The rainfall variability of both stations was very high $(\mathrm{CV}>30)$ in all months and seasons. Notched box plots of both stations are shown in Fig. 1. The highest seasonal IQR was recorded in monsoon at both stations with values of $203 \mathrm{~mm}$ and $312.25 \mathrm{~mm}$ at Baramati and Shivajinagar, respectively. The IQR of annual rainfall was $213.4 \mathrm{~mm}$ at Baramati and $267.65 \mathrm{~mm}$ at Shivajinagar. Box plots and CS values (Table 1) indicate that the rainfall data of both stations were positively (right) skewed. The presence of several outliers in the box plots indicates extreme rainfall events during 1969-2019. It is also inferred from the box plot that both stations do not meet the assumption of normal distribution, and hence, applying non-parametric methods with parametric methods is essential.

\section{Trends of rainfall using $M K, M M K$ and SRC}

The $\mathrm{Z}$ statistic of MK, MMK, and SRC test are summarized in Tables 2 and 3,for both stations. In Baramati, significant rainfall trends were observed in the months of June and July. Rest of the months have no significant trends of rainfall. The $Z$ values of MMK3 and MMK6 of June showed statistically significant increasing trends at $1 \%$ and $10 \%$ level of significance, respectively. In July the positive $\mathrm{Z}$ values of MK, MMK4, MMK6 and SRC were significant at $10 \%$ level, MMK2 and MMK5 at 5\% level while the $\mathrm{Z}$ values of MMK1 and MMK3 were significant at 1\% level of significance. The monsoon and post-monsoon rainfalls in
Baramati has increasing and decreasing trends of rainfall, respectively. All the tests yield positive values of $\mathrm{Z}$ test statistic for monsoon and negative values for post-monsoon. But only the $\mathrm{Z}$ value of MMK3 were significant for both seasons. The increasing trend in monsoon and the decreasing trend of post-monsoon was significant at 5\% level. The results of all the tests for winter, pre-monsoon and annual rainfall were non-significant. Shivajinagar had significant values of the trend from February to June and September. The rest of the months have no significant trend of rainfall. In February, the $\mathrm{Z}$ values of MK, MMK3 and SRC depicted significantly decreasing rainfall trend at 5\% level of significance, while the negative $\mathrm{Z}$ of MMK2 was significant at $10 \%$ level. March has a significantly falling slope of simple linear regression at 5\%. In April, $Z$ values of MK MMK1, MMK2, MMK4 and SR showed significantly decreasing trends at 10\% level. The $\mathrm{Z}$ values of MK, MMK1 and MMK2 were the same. $Z$ values of MMK5 and MMK6 were significantly negative at 5\% while MMK3 showed negative trends at $1 \%$ level of significance. In May, negative trends were shown by $\mathrm{Z}$ values of MK, MMK4 and MMK5 significant at 5\% level, while the $\mathrm{Z}$ values of MMK1, MMK2, MMK3 and MMK6 values showed significantly decreasing rainfall trends at $1 \%$ level of significance. The $\mathrm{Z}$ values of MMK1 and MMK2 were the same for May. The decreasing trend of May as per $\mathrm{Z}$ values of SRC was significant at 5\% level whereas the 
Table 3: Results of the statistical tests for rainfall over the period 1969-2019 for Shivajinagar

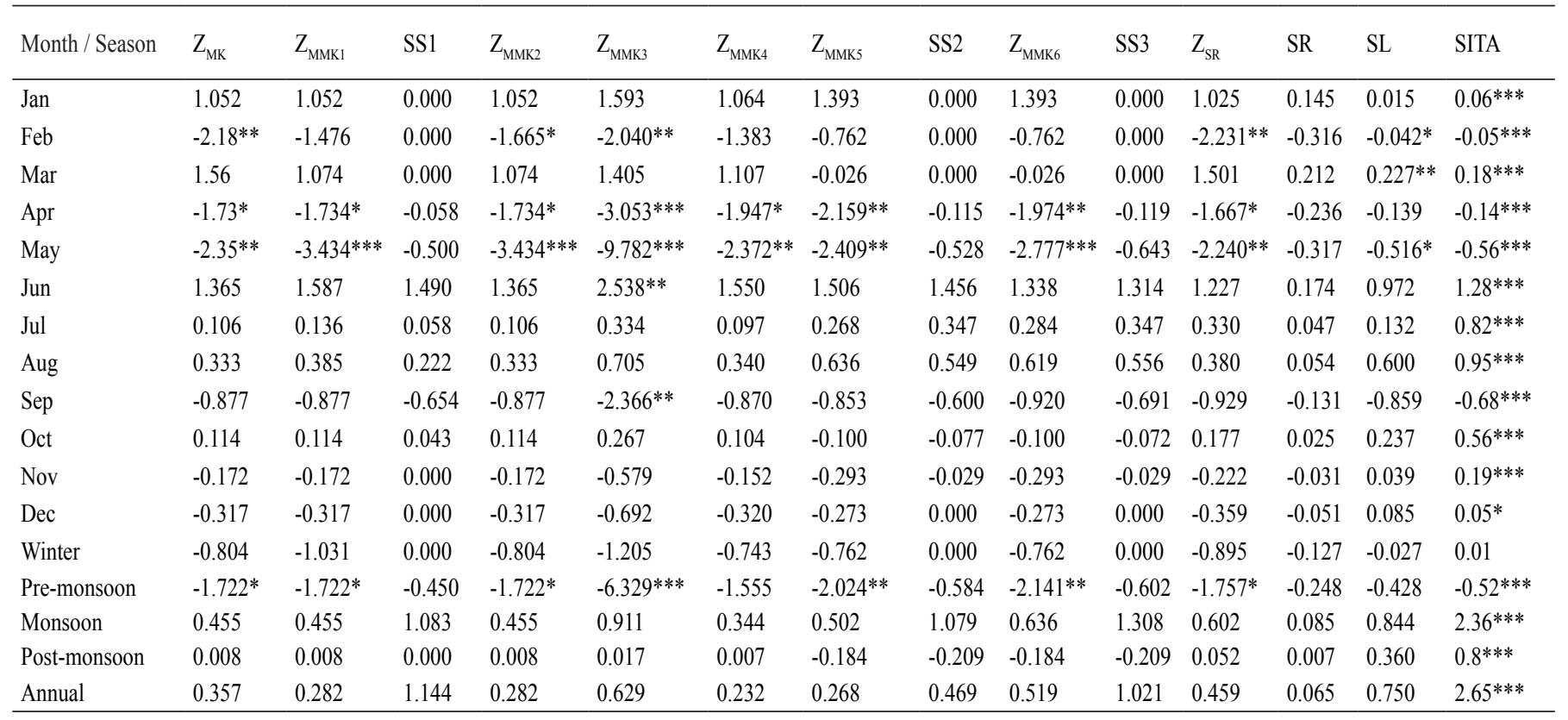

* Significance at $\mathrm{p} \leq 0.1 ; * *$ significance at $\mathrm{p} \leq 0.05 ; * * *$ significance at $\mathrm{p} \leq 0.01$; Bold font represent trends identified only by ITA

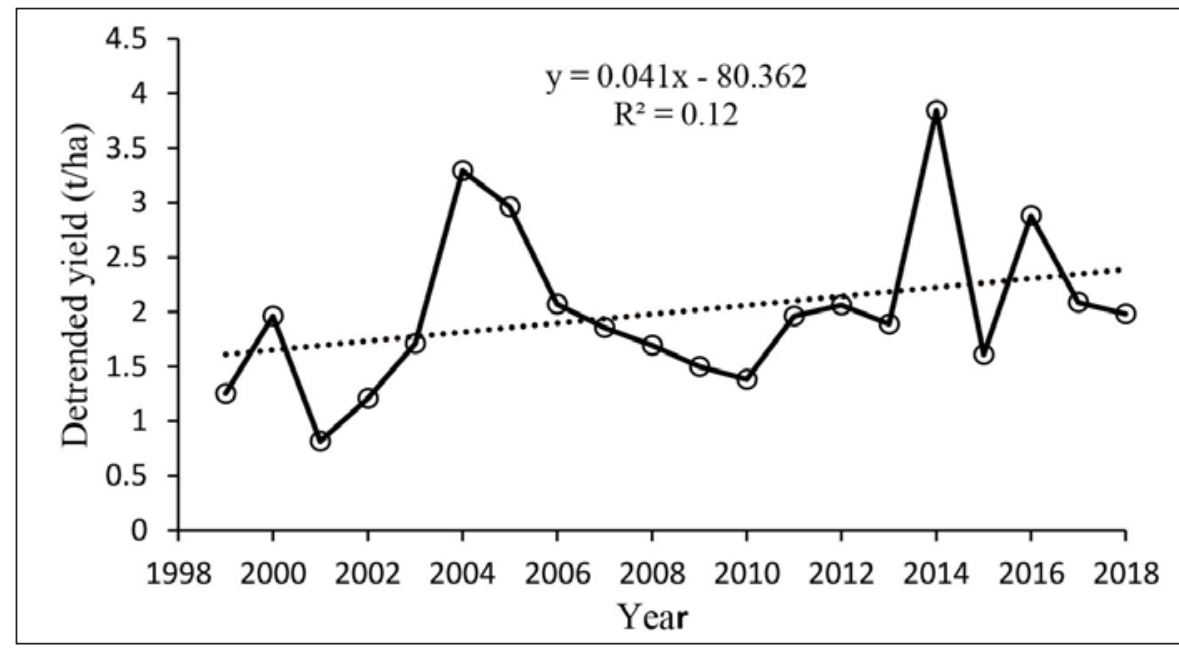

Fig. 3: De-trended soybean yield in western Maharashtra region during 1999-2018 period.

negative slope of simple linear regression was significant at $10 \%$ level. In June, positive trends were obtained from each test, however, only the $\mathrm{Z}$ value of MMK3 was significant at $5 \%$ level. Similarly, in September all the tests depicted decreasing trends, and only MMK3 has significant $Z$ value at a $5 \%$ level. On seasonal scale, only the pre-monsoon rainfall has significant decreasing trends. The rest of the seasons as well as annual rainfall have no statistically significant trends. In pre-monsoon, $\mathrm{Z}$ values of MK, MMK1 and MMK2 have the same significant negative values at $10 \%$ level. The $Z$ values of SRC is also significantly negative at $10 \%$ level. The
Z statistic of MMK5 and MMK6 were significantly negative at $5 \%$ level. $\mathrm{Z}$ statistic of MMK3 was significantly negative at $1 \%$ level. The monsoon and annual rainfall of the station have non-significant increasing trends as depicted by all the tests.

\section{Magnitude rainfall from $S S, S R$ and $S L$}

The magnitude of trends in the rainfall time series of the two stations was analyzed by Sen's slope (SS1, SS2 and SS3), Spearman's Rho (SR), and slope of simple linear regression (SL). The results are being summarized in 

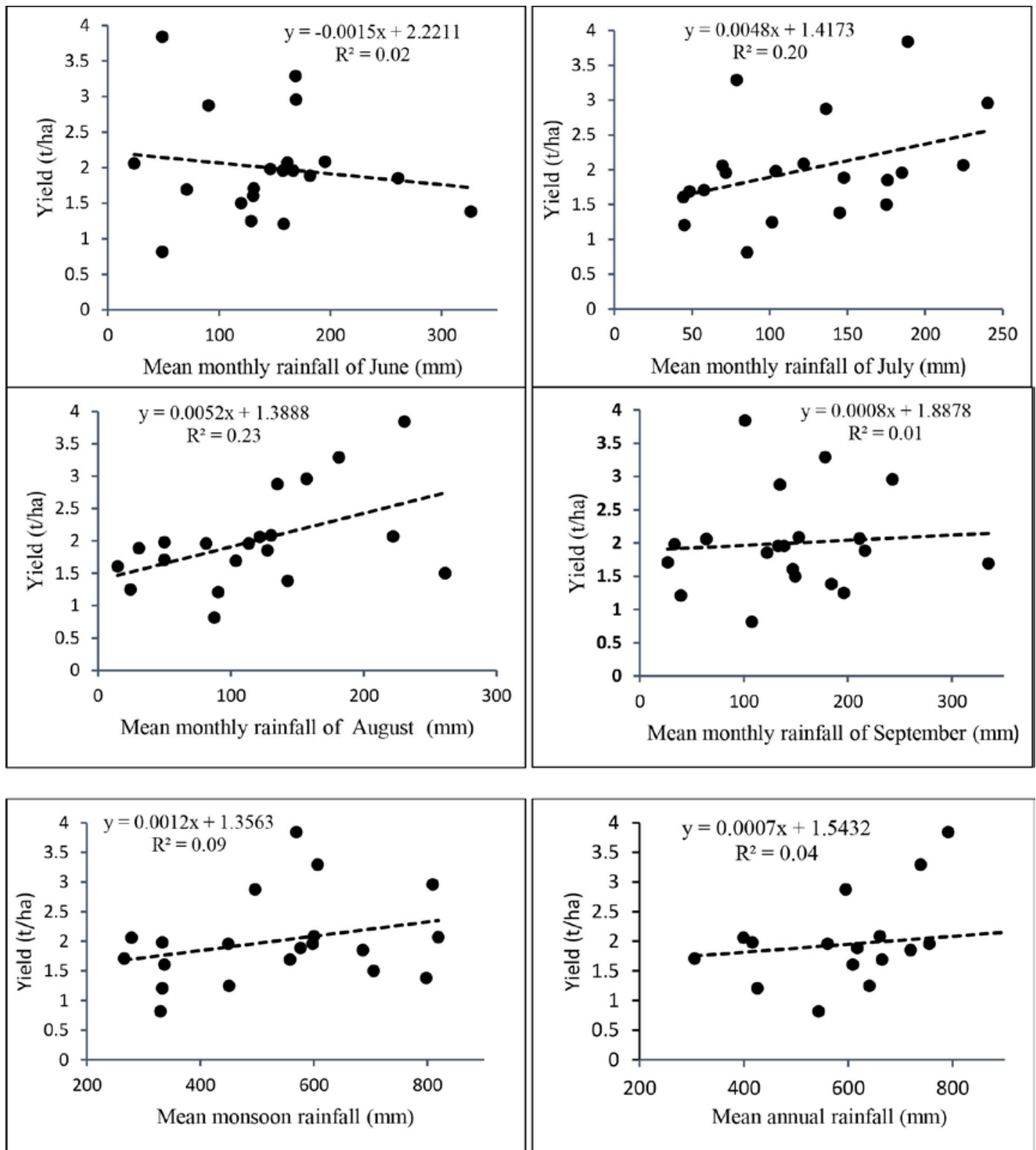

Fig. 4: Linear regression analysis of rainfall and de-trended soybean yield during1999-2018.

Tables 2 and 3. In Baramati, SS3 of June (1.17) showed a significantly increasing magnitude of trends at $10 \%$ level. SS1, SS2 and SS3 of July $(0.692,0.821$ and 0.771$)$ showed a statistically significant increase in rainfall at $1 \%, 5 \%$ and $10 \%$, respectively. The SR of July (0.235) was also significant at $10 \%$ level. SL was non-significant for all months and seasons as well, in Baramati. Rainfall in Shivajinagar had a falling magnitude of trend in February with SR (-0.316) and SL $(-0.042)$ significant at 5\% and 10\% level, respectively. The SS1 was also significant at $5 \%$ but the value was nearly zero. SL of March showed a significantly rising slope of rainfall trend at the rate of $0.227 \mathrm{~mm} /$ year. In April, SS1 (-0.058) and SR (-0.236) showed a falling magnitude of rainfall trend significant at $10 \%$, while the SS2 (-0.115) and SS3 (-0.119) showed significant falling magnitude of rainfall trend at $5 \%$ level. The SS3 (-0.643) of May showed significant negative magnitude of trend at $1 \%$ level, SS1 (-0.500), SS2 $(-0.528)$, SR $(-0.317)$ at $5 \%$ and SL $(-0.516)$ at $10 \%$ level. In the seasonal data, only pre-monsoon has significant falling magnitude with SS1 (-0.450) and SR (-0.248) significant at $10 \%$, while the SS2 (-0.584) and SS3 (-0.602) at 5\% level. On seasonal scale, only the pre-monsoon rainfall has significant decreasing trends. The rest of the seasons as well as annual rainfall have no statistically significant trends. 


\section{Trend and magnitude of rainfall using the new ITA}

The ITA results indicated more number of significant results as compared to all other trend detection methods at both stations (Tables 2 and 3). In Baramati, ITA revealed significant negative slope of rainfall in January (-0.05), October (-0.38) and November $(-0.31)$ at $1 \%$ level. The increasing slope of rainfall trend in March (0.17), June (1.26) and July (0.34) were significant at $1 \%$ level. September has decreasing rainfall slope $(-0.4)$ at $10 \%$ level of significance. Winter $(-0.07)$ and post-monsoon $(-0.88)$ has have decreasing while pre-monsoon (0.34) and monsoon (1.23) has significantly increasing slope of rainfall trends at $1 \%$ level. The annual rainfall in Baramati have significantly increasing slope (0.63) of rainfall trends at $10 \%$ level. In Shivajinagar, except winter season, the ITA results indicated significant trend results for all months, seasons, and annual rainfall. The slopes of rainfall trend for January (0.06), March (0.18), June (1.28), July (0.82), August (0.95), October (0.56) and November (0.19) along with monsoon (2.36), post-monsoon (0.8) and annual (2.65) rainfall were rising significantly at $1 \%$ level as depicted by ITA. December has significantly increasing slope of 0.05 at $10 \%$ level. February (-0.05), April (-0.14), May (-0.56), September (-0.68) and pre-monsoon (-0.52) has decreasing slopes of rainfall significant at $1 \%$ level.

\section{Impact on agricultural crop}

Soybean is the most important oilseed crop of Maharashtra and cultivated as rainfed crop in the state's drought prone western parts.It requires up to $700 \mathrm{~mm}$ of water during its growth period for optimum yield (FAO, 2020). As the lack of irrigation facility during crop growth period is the second most important constraint faced by $81.2 \%$ farmers of Maharashtra after labor issue (Jaybhay et al., 2016), the rainfall during the growing season and its variations are major determinant of soybean production in the region. The de-trended yield showed an increasing trend over the region (Fig. 3). The linear regression analysis of de-trended soybean productivity with mean monthly (growing season months), seasonal and annual rainfall are shown in Fig 4. The results indicated an overall direct positive relationship during the period 1999-2018, except for June. The rainfall in June increases the soil moisture, which delays the planting and also hampers the germination of the seeds, which may be the reason for the inverse relation. As the amount of rainfall is a key constraint on crop productivity, the increasing monsoon and annual rainfall trends may be one of the reasons for increasing trends of soybean productivity in the region.
Rainfall is one of the significant individual climatic factor associated with crop production system (Pradhan et al., 2020) and hence the overall increasing rainfall trends in the region may help in sustaining the soybean productivity under climate change scenario.

\section{CONCLUSION}

Our study reveals significant changes in monthly, seasonal and annual rainfall in the study area during the past 51 years. Considering MK, MMK, SRC and SLR tests: Baramati has increasing rainfall in June, July, pre-monsoon season while in the post-monsoon season it has decreasing trends, and Shivajinagar has decreasing rainfall in February, April, May, September and pre-monsoon, whereas the rainfall in June has increasing trends. Considering ITA method: Baramati has increasing rainfall trends in March, June, July, pre-monsoon, monsoon as well as annual scale while in January, September, October, November, Winter and post-monsoon the rainfall is decreasing, and in Shivajinagar, February, March, May, September and pre-monsoon has decreasing trends and rest of the monthly, seasonal and annual rainfall have increasing trends. Along with the trends in 11-time series (out of 34-time series analyzed) which are detected by MK, MMK, SRC and SLR tests, ITA also detected significant trends in 17-time series that was not detected by any of the aforementioned tests, which indicates ITA is a more powerful test for trend detection. The increasing trends of monsoon and annual rainfalls in western Maharashtra will be helpful in improving the productivity of agricultural crops in the region.

\section{REFERENCES}

FAO (2020).Water Harvesting. http://www.fao.org/3/u3160e/ u3160e04.htm.

Haan, C.T. (2002). Statistical methods in hydrology. $2^{\text {nd }}$ Edition. The Iowa State University Press, Iowa, USA.

Hamed, K.H., and Ramachandra Rao., A. (1998). A modified Mann-Kendall trend test for autocorrelated data. $J$. Hydrol., 204 (1-4):182-196.

Kendall, M.G. (1975). Rank correlation measures. 4th eds Charles Griffin, London, pp.220.

Lehmann, E.L.,and D'Abrera, H.J. (1975). Nonparametrics: statistical methods based on ranks. Holden-Day., pp.457. 
Mann, H.B. (1945). Nonparametric Tests Against Trend. Econometrica,13(3):245.

Pradhan, A., Chandrakar, T., Nag S.K., Dixit, A., and Mukherjee S.C. (2020). Crop planning based on rainfall variability for Bastar region of Chhattisgarh, India. J. Agrometeorol. 22 (4): 509-517.

Rao, A.R., Hamed, K.H.,and Chen, H.L. (2012). Nonstationarities in hydrologic and environmental time series. Springer Science \&Business Media, pp.365.

Sen, P.K. (1968). Estimates of the Regression Coefficient Based on Kendall's Tau. J. Am. Stat. Assoc.,63(324) :1379-1389.

Şen, Z. $(Y \cdot \mid r)$. Innovative Trend Analysis Methodology. $J$. Hydrol. Eng., 17:1042-1046.

Sinha, H.K., Manikandan, N., Chaudhary, J.L. and Nag S. (2020). Extreme rainfall trends over Chhattisgarh state of India. J. Agrometeorol. 22 (2): 215-219.

Sneyers, R. (1990). On the statistical analysis of series of observations. WMO Technical Note 143. World Meteorological Organization, Geneve, pp.192.
Subash, N., and RamMohan, H.S. (2012). Evaluation of the impact of climatic trends and variability in ricewheat system productivity using Cropping System Model DSSAT over the Indo-Gangetic Plains of India. Agric. For. Meteorol., 164:71-81.

Yue, S., Pilon, P., Phinney, B., and Cavadias, G. (2002). The influence of autocorrelation on the ability to detect trend in hydrological series. Hydrol. Process., 16 (9) :1807-1829.

Yue, S., and Wang, C.Y. (2004). The Mann-Kendall test modified by effective sample size to detect trend in serially correlated hydrological series. Water Resour. Manag., 18 (3) :201-218.

Yue, S., and Wang, C.Y. (2002). Applicability of prewhitening to eliminate the influence of serial correlation on the Mann-Kendall test. Water Resour. Res., 38 (6):4-1.

Von Storch, H. (1999). Misuses of statistical analysis in climate research. In: Analysis of climate variability (Eds.H.Von Storch andA.Navarra). pp.11-26, Springer, Berlin, Heidelberg. 